\title{
Expander-generator set for utilization of natural gas overpressure energy
}

\author{
A A Mukolyants ${ }^{1}$ I V Sotnikova ${ }^{1}$, D K Ergasheva E $^{\text {, A A Taubaldiev }}{ }^{1}$ \\ ${ }^{1}$ Tashkent State Technical University named after Islam Karimov University street №2, Tashkent city; Uzbekistan \\ E-mail: arsen5675@mail.ru
}

\begin{abstract}
Annotation: The article deals with the problem of using secondary energy resources in the system of transportation and distribution of natural gas, and the possibility of generating electricity without burning fuel by reducing high-pressure natural gas at gas distribution stations. The analysis of the influence of the gas temperature at the entrance to the expander - generator unit, as well as the dependence of the power of the expander - generator unit on the gas temperature and the temperature of the low-potential source is presented. Optimal temperatures are obtained at which the power of the expander-generator unit is maximal for the given gas parameters.
\end{abstract}

\section{Introduction}

Currently, in the context of rising prices and increasing demand for energy resources, the problem of energy conservation and the use of non-traditional energy sources is of particular importance.

The problem of energy conservation, which is one of the most important in all developed countries, is becoming particularly acute in Uzbekistan. Reducing the specific energy intensity of the economy is the main task of Uzbekistan's energy policy, without which the energy sector will inevitably constrain the country's socioeconomic development. The forecast estimate shows that in the period up to 2030, the annual growth of electricity consumption in the Republic of Uzbekistan will be about 6-7 \%, and therefore the main goal of the Concept of Providing Electric Energy for 2020-2030 is to meet the growing demand for electric energy at competitive prices and the dynamic development of the electric power industry.

In this regard, the issue of distributed power generation from secondary energy resources for further growth of energy saving becomes relevant.

On the territory of Uzbekistan there is a large number of gas distribution stations (GDS), where the potential energy of pressure is lost during reduction.

One of the directions of energy saving at GDS is the use of expander-generator units (EGU) for generating electricity by using the technological differential pressure of gas in gas supply systems. In the world practice, considerable experience has been accumulated in the successful operation of EGU. Scientific and technical periodicals give a high assessment of the efficiency of EGU, which is determined, first of all, by lower specific capital expenditures and specific fuel consumption for electricity generation than at steam turbine power units [13].

The efficiency of electricity production using expander technologies is twice as high as at modern power plants.

\section{Materials and research methods}

To increase the efficiency of the expander generator set, it is necessary to increase the temperature of the gas before entering the unit. The efficiency of the DGA depends on the method of heating the gas before the expander. In addition, the technological requirements for the operation of gas pipelines make it necessary to heat the gas before the DGA expander to a temperature of $80-100^{\circ} \mathrm{C}$.

Let's consider the schematic diagram of switching on a gas distribution station (Fig.1).

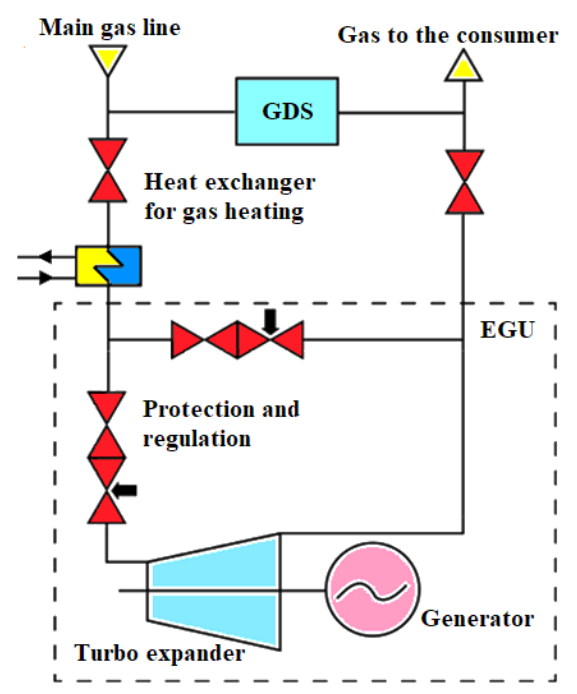

Fig.1. Diagram of the gas expansion complex GDS with EGU 
Expander it is connected in parallel to the throttle device, replacing it partially or completely. When the gas expands in the expander, the flow temperature drops much more than during throttling. Without preheating before the expander, the gas temperature may be lower than the temperature at which the operation of gas pipelines is impossible. For this reason, in addition to the expander and the electric generator connected to it, the EGU includes a heat exchanger for heating gas in front of the expander [47].

Preheating the gas to the EGU can be carried out to a certain value, since the temperature of the exit from the EGU must be kept in the range from 22 to $30{ }^{\circ} \mathrm{C}$. This is primarily due to the fact that there is an impact of gas, at temperatures above the permissible temperature, on the pipeline, which can lead to wear.

The heating temperature ranges from 30 to $100{ }^{\circ} \mathrm{C}$. The choice of temperature is made for technical and economic reasons, since further increase in temperature leads to costs when supplying a third-party heat source. The heat source can be waste heat from a thermal power plant (if the GDS is located in the vicinity), a heat pump installation.

Usually, to increase the temperature, the thermal energy obtained by a heat pump unit operating on a low-potential working body is used.

If the heat source is a heat pump unit, then the temperature of the low-potential heat source must also be taken into account.

The results of studies show [8-10] that the optimal value of the gas temperature entering the expander corresponds to the maximum useful power of the system. Experiments show that the optimal gas temperature at the expander inlet increases from 60 to $80{ }^{\circ} \mathrm{C}$.

\section{Research results and discussion.}

The calculation of the turbo expander power was made under certain assumptions that were made to simplify the calculation without significantly reducing its reliability.

Temperatures at the entrance to the EGU were assumed from +30 to $+80{ }^{0} \mathrm{C}$ to obtain the dependence of the potential power on the gas temperature at the entrance to the EGU.

Enthalpy difference in the adiabatic gas expansion process, $H_{\mathrm{AD}}, \mathrm{kJ} / \mathrm{kg}$, in the expander generator is calculated by the formula:

$$
H_{\mathrm{AD}}=\frac{k}{k-1} \cdot z \cdot R \cdot T \cdot\left(1-\left(\frac{P_{\text {output }}}{P_{\text {input }}}\right)^{\frac{k-1}{k}}\right),
$$

where $\mathrm{z}$ - is the compressibility factor;

$k$ - adiabatic volume index;

$R$ - individual gas constant, $\mathrm{J} / \mathrm{kg} \cdot \mathrm{K}$;

$T$ - the gas inlet temperature of the EGU, ${ }^{0} \mathrm{~K}$.

Natural gas mass flow rate G, through the GBS,

$\mathrm{kg} / \mathrm{s}$ :

$$
G=\frac{Q \times p_{\text {mix }}}{3600}
$$

Rated available power of EGU $N_{\mathrm{EGU}}, \mathrm{kW}$ :

$$
N_{\mathrm{EGU}}=G \cdot H_{\mathrm{AD}} \cdot \eta \text {, }
$$

where $\eta$ is the efficiency of the expander-generator unit.

For the calculation, the average gas parameters for the gas distribution system of the average industrial consumer in the Republic of Uzbekistan were taken (Table 1).

Table 1. Gas parameter table

\begin{tabular}{|c|l|c|}
\hline $\begin{array}{l}\text { Gas consumption } \\
Q, m^{3} / \mathrm{h}\end{array}$ & $\begin{array}{l}\text { Inlet pressure } \\
P_{\text {input }}, \mathrm{MPa}\end{array}$ & $\begin{array}{l}\text { Output pressure } \\
P_{\text {output }}, \mathrm{MPa}\end{array}$ \\
\hline 41000 & 19 & 6 \\
\hline
\end{tabular}

According to the given data and the method of analysis, the results of calculations were obtained(Table 2).

Table 2. Calculation results

\begin{tabular}{|c|c|}
\hline $\begin{array}{c}\text { Gas temperature at the inlet } \\
\text { to the EGU, }{ }^{0} \mathrm{C}\end{array}$ & Power of the EGU, $\mathrm{kW}$ \\
\hline 30 & 923,8 \\
\hline 40 & 954,2 \\
\hline 50 & 984,7 \\
\hline 60 & 1015,2 \\
\hline 70 & 1045,7 \\
\hline 80 & 1076,2 \\
\hline
\end{tabular}

To obtain the optimal temperature values for heating gas to EGU, a graph of the dependence of the useful power of the EGU and the gas temperature is given based on the data obtained during the calculation (Fig.2).

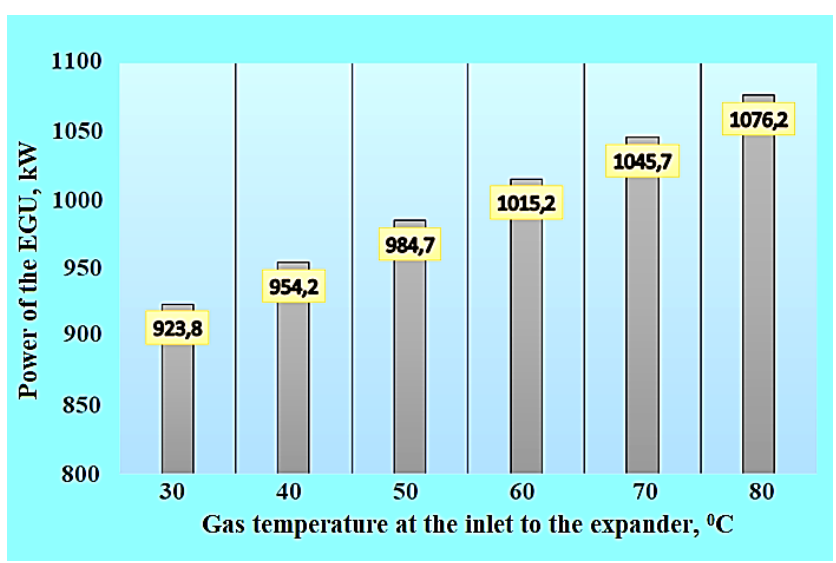

Fig. 2. Dependence of the useful power of the EGU on the gas temperature at the inlet to the expander

The above calculation is made without taking into account the energy consumption for heating gas to EGU. For a more accurate analysis of the dependence of the useful power of the EGU obtained by subtracting the power consumed by the heat pump unit, a graph of the dependence of the useful power of the EGU on the gas temperature at the gas inlet and the temperature of the lowpotential heat source is shown (Fig. 3.) 


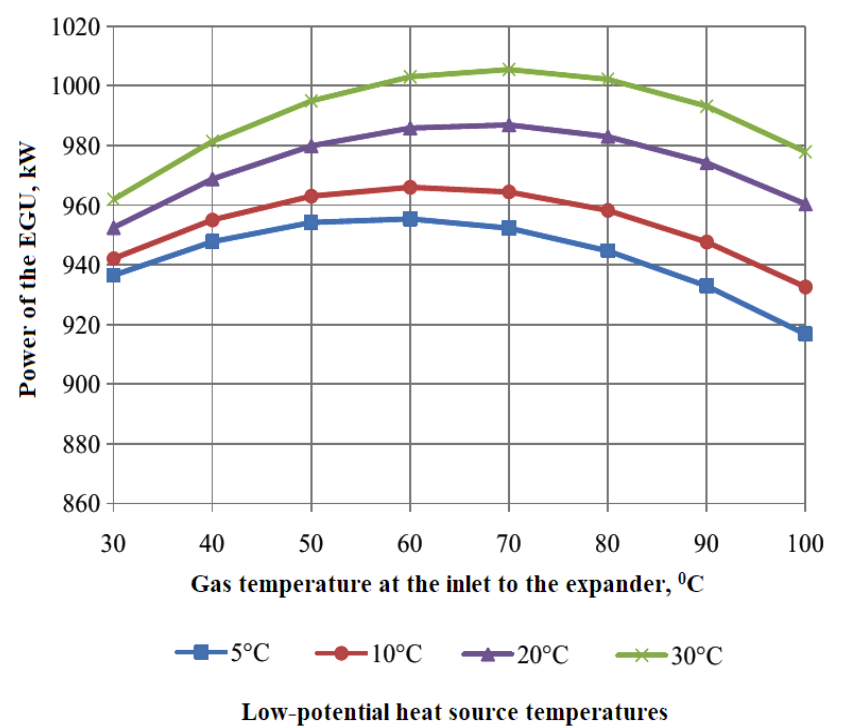

Fig. 3. Dependence of the useful power of the EGU on the gas temperature at the inlet to the expander and low-potential heat source temperatures

The temperature of a low-potential heat source has a large influence on the amount of power generated by the EGU. When the temperature of the low-potential heat source increases from 5 to $30{ }^{\circ} \mathrm{C}$, the part of the released power increases by $2.6-5.0 \%$, the higher the gas temperature in front of the expander, the greater the influence of the change in the temperature of the lowpotential heat source.

Figure 4 shows the dependence of the share of power released from the installation on the gas temperature at the inlet to the expander and the temperature of the lowpotential heat source.

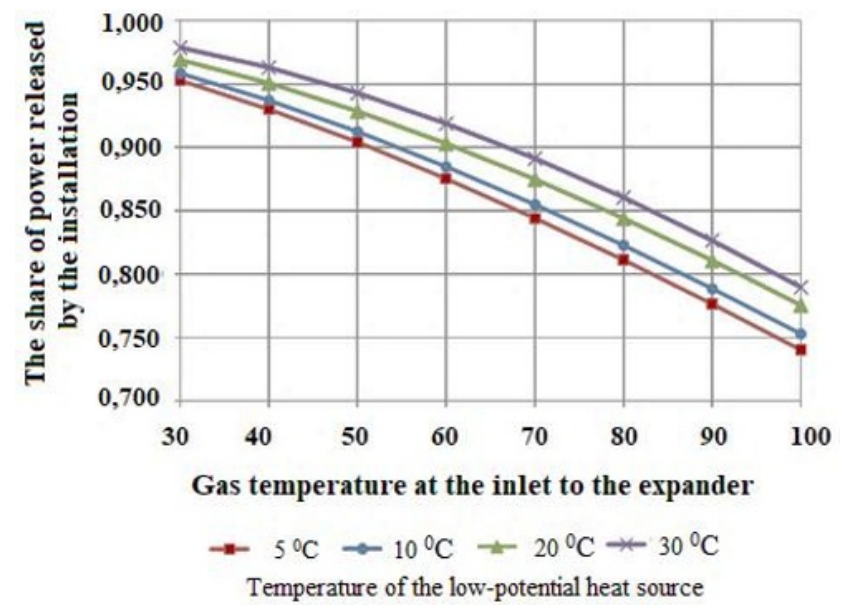

Fig. 4. Dependence of the share of power released by the expander-generator set on the gas temperature at the inlet to the expander and the temperature of the low-potential heat source

\section{Conclusion}

From the above analysis, it follows that the maximum useful power of the EGU corresponds to the temperature at the entrance to the expander $70{ }^{\circ} \mathrm{C}$ and the low temperature of the heat source $30{ }^{\circ} \mathrm{C}$. The share of power supplied by the EGU monotonically decreases with increasing gas temperature at the expander inlet. This dependence is explained by the ratio of the power generated by the expander and the power of the plant's own needs.

The power of the expander increases with increasing gas temperature at the expander inlet, while the power of its own needs also increases (mainly due to an increase in the power consumed by the compressor of the heat pump unit).

Thus, it is possible to draw a conclusion about the high economic efficiency of the investment project for the introduction of EGU at the enterprise of the electric power industry. Currently, EGU implementation projects demonstrate minimal payback periods for capital investments when compared with any other types of power equipment, both in the traditional "big" power industry, and for small and non-traditional power installations. High indicators of economic efficiency of investment projects for the implementation of EGU are provided by minimal capital expenditures and minimal costs for the operation of power plants using optimal tariff and taxation models in accordance with the current legislation Republic of Uzbekistan.

\section{References}

1. Conceptions of "Providing the Republic of Uzbekistan with electric energy for 2020-2030" [Electronic resource]: http: / /www.minenergy.uz.

2. Buranov, M., Mukolyants, A. and Sotnikova, I. (2019) Generation of electrical energy at gas pipelines using a transported natural gas technological pressure drop. J. Phys.: Conf. Ser. 1399055038 https://doi:10.1088/1742-6596/1399/5/055089

3. Kerimov I.A., Saidov A.-V.A., Batayev D.K.-S., Debiyev M.V. Economical aspects of use of detander-generating units in system of gas networks of Chechen republic. Вестник ТГУ, т.17, вып.2, 2012

4. A A Mukolyants, M D Buranov, I V Sotnikova and $\mathrm{H} \mathrm{F}$ Makhmudov. Operation analysis of expander-generator unit at a gas distribution station. Journal of Physics: Conference Series. 2020. Journal of Physics: Conference Series 1515 022053 $6596 / 1515 / 2 / 022053$

5. Mukolyants A.A., Buranov M.D., Sotnikova I.V., Makhmudov H.F. The expander-generator unit at a gas distributing station of magistral gas pipeline. The collection includes16th the International Scientific and Practical Conference "Science and Society" by SCIEURO in London 23-28 February. №1, 2020.-p.8-16.

6. Mukolyants Arsen Artyomovich, Buranov Mardon Davronovich, Sotnikova Irina Vladimirovna, Azimova Munira Muminovna. Analysis of the influence of the input parameters on the efficiency of the operation of the detander generator unit in the gas network system of the 
republic of Uzbekistan. E3S Web of Conferences 216, 01130 (2020)

https://doi.org/10.1051/e3sconf/202021601130

7. Taslimov A, Berdishev A, Melikuzuev $\mathrm{M}$ and $\mathrm{F}$ Rakhimov 2019 E3S Web of Conferences B 139 010https://doi.org/10.1051/e3sconf/20191390 1077

8. Agababov V, Koryagin A, Utenkov $\mathrm{V}$ and Khaymer Yu 2000 J.Gas-Erdgas gwf. B 9 610615

9. Taslimov A., Rakhmonov, I. (2019) J. Phys.: Conf. Ser. 1399055046 doi:10.1088/17426596/1399/5/055046

10. Mukolyants A.A., Sotnikova I.V., Buranov M.D., Taubaldiyev A.A., Improving the efficiency of air transport heat pump unit in the expandergenerator unit, German International Journal of Modern Science №8, 2021. DOI: 10.24412/27018369-2021-8-1-49-51 